\title{
NanoDisk containing super aggregated amphotericin B: a high therapeutic index antifungal formulation with enhanced potency
}

This article was published in the following Dove Press journal:

International Journal of Nanomedicine

II December 2013

Number of times this article has been viewed

\author{
Braydon L Burgess ${ }^{1,2}$ \\ Yumin $\mathrm{He}^{\prime}$ \\ Mandie M Baker ${ }^{1,2}$ \\ Bing Luo ${ }^{2}$ \\ Stephen F Carroll ${ }^{2}$ \\ Trudy M Forte ${ }^{2}$ \\ Michael N Oda' \\ 'Children's Hospital Oakland \\ Research Institute, Oakland, CA, USA; \\ ${ }^{2}$ Lypro Biosciences, Berkeley, CA, USA
}

Correspondence: Michael N Oda Children's Hospital Oakland Research Institute, 5700 Martin Luther King Jr Way, Oakland, CA 94609, USA

$\mathrm{Tel}+\mathrm{I} 5104507652$

Email moda@chori.org
Objectives: NanoDisk-amphotericin B (ND-AMB) is a protein-phospholipid bioparticle containing a "super aggregate" form of antifungal AMB. While lipid-based formulations of AMB, including liposomal AMB (L-AMB), are safer than the deoxycholate (DOC) solubilized form (DOC-AMB), the potency of lipid-based formulations is attenuated. We have developed an AMB-based therapy that is both well tolerated and fully efficacious.

Methods: Potency was determined using broth culture growth-inhibition assays and candidacidal kinetics by quantitative culture plating. Toxicology studies were performed in healthy mice. Efficacy was assessed using both immune-competent and leukopenic murine models of systemic Candida albicans infection.

Results: ND-AMB C. albicans and Aspergillus fumigatus minimum inhibitory concentrations were fourfold and sixfold lower, respectively, than that observed for L-AMB. ND-AMB exhibited candidacidal activity at $0.125 \mathrm{mg} / \mathrm{L}, 16$-fold lower than L-AMB. In mice, ND-AMB produced no statistically significant kidney or liver toxicity at $15 \mathrm{mg} / \mathrm{kg}$, the highest dose tested. When evaluated in immune-competent mice infected with $C$. albicans, ND-AMB was at least as effective as DOC-AMB or L-AMB. In a leukopenic model of candidiasis, the $50 \%$ effective dose of ND-AMB was around threefold lower than L-AMB.

Conclusion: These results indicate that ND-AMB exhibits a more favorable safety profile while maintaining uncompromised antifungal properties compared to both DOC-AMB and L-AMB. ND-AMB is a promising therapy for the treatment of invasive fungal infections.

Keywords: nanoparticles, infectious diseases, drug delivery, candidiasis, apolipoprotein A-I

\section{Introduction}

Amphotericin B (AMB) remains a clinically important therapy for the treatment of invasive fungal infections, even after 60 years on the market. This is because AMB has several key advantages over other classes of antifungal agents: 1) it has broad-spectrum activity against a wide range of medically relevant fungi, and 2) virtually no resistant pathological strains have developed. In contrast, pathogenic fungi resistant to azole and echinocandin antifungal drugs are now a serious concern. ${ }^{1-4}$ These traits make AMB an ideal therapy for patients with unidentified invasive fungal infections.

Despite its efficacy, safety concerns with deoxycholate-solubilized AMB (DOCAMB, Fungizone ${ }^{\circledR}$ ) have created barriers to AMB's clinical application. Dose-limiting nephrotoxicity and infusion reactions are not uncommon with AMB therapy. More recently, lipid-associated formulations of $\mathrm{AMB}$, including AmBisome ${ }^{\circledR}$ (liposomal $\mathrm{AMB}[\mathrm{L}-\mathrm{AMB}])$ and Abelcet $^{\circledR}$ have become commonly used due to their improved safety profiles. 
The protective effect of lipids in these formulations may originate from the stability of the lipid-drug interaction. AMB's toxicity to mammalian cells is believed to require the release of oligomeric forms of the drug from the carrier in blood, which occurs more slowly from lipid-AMB complexes than from DOC-AMB due to the unstable association between AMB and DOC micelles in the latter. ${ }^{5}$

L-AMB produces a significantly lower incidence of nephrotoxicity and infusion reactions when administered at typical therapeutic doses (3-6 mg/ $\mathrm{kg} /$ day) compared to DOCAMB therapy $(0.5-1.5 \mathrm{mg} / \mathrm{kg} /$ day $){ }^{6}$ However, higher doses of lipid-associated forms of $\mathrm{AMB}$ are required to achieve therapeutic results equivalent to DOC-AMB. ${ }^{7}$

Although AMB is a highly potent antifungal agent, it also exhibits significant cytotoxicity for mammalian cells. However, its toxicity towards mammalian cells can be reduced independently of fungicidal activity by controlling the aggregation state of the drug. Small aggregates or soluble oligomers, including those released by the DOC-AMB formulation, show the highest toxicity to mammalian cells and are usually the predominant species. ${ }^{8}$ Under certain conditions, formulations of AMB can be induced to contain a high percentage of "super aggregate" AMB. These formulations exhibit full antifungal activity and highly attenuated toxicity. ${ }^{9-12}$ AMB formulations containing a high proportion of super aggregated drug are therefore predicted to have an increased therapeutic index relative to those composed predominantly of small aggregates or soluble oligomers.

The size and percentage of AMB in aggregate structures can be monitored by absorbance spectroscopy. Monomers display a characteristic absorbance spectrum with several maxima between 330 and $416 \mathrm{~nm}$ in dimethyl sulfoxide (DMSO). In contrast, aggregates and super aggregates exhibit an increasingly singular absorbance maxima that is progressively blue-shifted in oligomers and super aggregated forms. This spectral shift suggests a highly organized structure in which the polyene chromophore of AMB is sequestered within a nonpolar environment. ${ }^{12,13}$

The application of heat to AMB induces a significant shift in the equilibrium of self-associated states towards the super aggregated form in both aqueous and lipid environments. ${ }^{11-13}$ The shift in aggregation state induces reduction in the cytotoxicity of AMB towards mammalian cells while maintaining its fungicidal efficacy. This preparative treatment can thus be used to improve the therapeutic index of the drug.

We have developed a novel formulation of NanoDisk (ND) containing super aggregated AMB for the treatment of invasive fungal infections. The ND drug-delivery vehicle is a complex consisting of a scaffold protein, apolipoprotein A-I (ApoA-I), a phospholipid bilayer, and a bioactive cargo (in this case, AMB). Prior work has demonstrated that drugs incorporated into the ND delivery vehicle are fully solubilized and retain bioactivity compared to other forms of the drug. ${ }^{14-18}$ In those studies, ND-AMB loaded with AMB unenriched in super aggregate content had high antifungal potency and formed flattened discoidal structures with a thickness of $2.5 \mathrm{~nm}$, consistent with an interdigitated bilayer, as determined by electron and atomic force microscopy. ${ }^{16,17}$ The present study extends this initial observation and describes the development and characterization of ND containing AMB (ND-AMB) enriched in super aggregate content. The physical characteristics of the ND-AMB particles were determined using light-absorbance spectroscopy and electron microscopy. Safety and antifungal efficacy were evaluated in comparison to two commonly used formulations of AMB - L-AMB and DOC-AMB - using in vitro and in vivo approaches.

\section{Materials and methods}

\section{Reagents and chemicals}

AMB powder (United States Pharmacopeia grade) was obtained from Chemwerth Pharmaceuticals (Woodbridge, CT, USA). The antifungal agents AmBisome (Gilead, Foster City, CA, USA) and DOC-AMB (X-Gen, Big Flats, NY, USA), were prepared according to the manufacturer's instructions. 1,2-Dimyristoyl$s n$-glycero-3-phosphocholine (DMPC) and 1,2-Dimyristoyl$s n$-glycero-3-phospho-(1'-rac-glycerol) sodium salt (DMPG) were obtained from Avanti Polar Lipids (Alabaster, AL, USA). Phosphate-buffered saline (PBS) contained $20 \mathrm{mM}$ phosphate and $155 \mathrm{mM} \mathrm{NaCl}$ adjusted to $\mathrm{pH}$ 7.4. Recombinant human ApoA-I bearing an $\mathrm{N}$-terminal polyhistidine tag was expressed in Escherichia coli and purified as described previously. ${ }^{19}$

\section{Animals}

Female Balb/c (20-22 g) and CD-1 (18-20 g) mice (Charles River, Wilmington, MA, USA) were maintained on a standard rodent diet (Global Rodent 9028; Harlan Teklad, Indianapolis, IN, USA) in an Association for the Assessment and Accreditation of Laboratory Animal Care-certified facility at the Children's Hospital Oakland Research Institute. All procedures involving animals were reviewed and approved by the Institutional Animal Care and Use Committee.

\section{Fungi}

Candida albicans strain SC5314 and Aspergillus fumigatus isolate Af293 (American Type Culture Collection [ATCC], 
Manassas, VA, USA) were cultured at $35^{\circ} \mathrm{C}$ on yeast peptone dextrose or potato dextrose agar plates, respectively unless otherwise noted. To prepare inoculum for animal studies, a glycerol stock of $C$. albicans was streaked on Sabouraud dextrose agar and grown overnight at $30^{\circ} \mathrm{C}$, then several colonies were transferred to $5 \mathrm{~mL}$ Sabouraud dextrose broth and grown overnight at $30^{\circ} \mathrm{C}$. The culture was washed twice with sterile saline, then quantified by absorbance at $600 \mathrm{~nm}$ prior to use.

\section{AMB quantification}

All AMB-containing solutions described were quantified spectrophotometrically at $416 \mathrm{~nm}$ using an extinction coefficient of $1.214 \times 10^{5} \mathrm{~cm}^{-1} \mathrm{M}^{-1}$. Solutions were diluted at least 2,000-fold in DMSO prior to assay, and measurements were performed in triplicate. For spectra obtained in PBS, intact vehicle was diluted in PBS and the instrument was blanked against the buffer. Empty ND vehicle did not absorb significantly between 300 and $450 \mathrm{~nm}$ at this dilution.

\section{ND-AMB formulation}

ND-AMB was prepared as previously described, ${ }^{17}$ with minor modifications. Briefly, DMPC and DMPG were combined in chloroform at a 7:3 ratio $(w / w)$ in glass tubes and then dried under nitrogen. Lipid films containing $10 \mathrm{mg}$ total lipid were hydrated with $0.25 \mathrm{~mL}$ PBS and vortexed for 30 seconds before the addition of $10 \mathrm{mg}$ AMB dissolved at $50 \mathrm{mg} / \mathrm{mL}$ in DMSO and $4 \mathrm{mg}$ ApoA-I in $1 \mathrm{~mL}$ PBS. The mixture was sonicated until clear, typically 30-90 minutes, in a sonicating water bath $(50 \mathrm{HT}$; Crest Ultrasonics, Trenton, NJ, USA). The sonicated mixture reached a maximum of $35^{\circ} \mathrm{C}$ under standard conditions. Solutions were dialyzed for 48 hours against a minimum of 500 volumes of PBS at $4^{\circ} \mathrm{C}$ using a dialysis membrane with a $10 \mathrm{kDa}$ molecular weight cutoff. To produce super aggregated variants of ND-AMB, the dialyzed material was heated in thin-wall tubes using a thermocycler (BioRad, Hercules, CA, USA) between $50^{\circ} \mathrm{C}$ and $85^{\circ} \mathrm{C}$ for 30 minutes, as indicated by superscripts in the text, eg, ND-AMB ${ }^{72 C}$ indicates an incubation temperature of $72^{\circ} \mathrm{C}$. All ND-AMB formulations were sterile-filtered through polyethersulfone syringe filters $(0.2 \mu \mathrm{m})$ prior to use (Sartorius, Bohemia, NY, USA).

\section{ND-AMB characterization}

Uniformity of ND-AMB preparations was confirmed by spectrophotometry to determine drug incorporation and aggregation state of the AMB. When prepared as described, $\mathrm{ND}-\mathrm{AMB}^{72 \mathrm{C}}$ had a wavelength of maximal absorbance $\left(\lambda_{\max }\right)$ of $322-323 \mathrm{~nm}$, and drug incorporation was $60 \%-70 \%$.
These properties were stable for at least 6 weeks when solutions were stored undiluted $(3-4 \mathrm{mg} / \mathrm{mL} \mathrm{AMB})$ at $4^{\circ} \mathrm{C}$ and protected from light.

\section{Electron microscopy}

Negative-stain electron microscopy was used to visualize particle morphology. A small droplet of sample was deposited on a carbon-coated grid, and after 15 seconds excess fluid was wicked away and $2 \%$ potassium phosphotungstate, $\mathrm{pH} 6.5$, added. After 5-10 seconds, excess stain was removed and the grid air-dried. Grids were examined at $80 \mathrm{kV}$ in a JEM1230 electron microscope (JEOL USA, Peabody, MA, USA), and imaged with an UltraScan ${ }^{\text {TM }}$ USC1000 charge-coupled device camera (Gatan, Warrendale, PA, USA).

To measure particle diameter from digital images, the area of individual particles ( $n=100$ per formulation) was determined manually using ImageJ image-processing software, and diameter was calculated from the measured area by assuming a perfect circular shape.

\section{Minimal inhibitory concentration assays}

The minimal inhibitory concentration (MIC) of ND-AMB ${ }^{35 \mathrm{C}}$, ND-AMB ${ }^{72 C}$, L-AMB, and DOC-AMB were established for C. albicans (SC5314) and A. fumigatus (AF10). Organism culture, microplate assay, and scoring were performed using approved methods published by the Clinical and Laboratory Standards Institute. ${ }^{20,21}$

\section{Fungicidal assay}

C. albicans was streaked on Sabouraud dextrose agar, and then 1-day colonies were transferred to a broth culture of Roswell Park Memorial Institute (RPMI) buffered to $\mathrm{pH}$ 7.0 with 3-( $N$-morpholino)propanesulfonic acid and grown overnight. Next, one volume of stationary culture was added to four volumes warmed buffered RPMI, and growth was monitored until log-phase growth resumed. The culture was further diluted with buffered RPMI to $\sim 1 \times 10^{5}$ colony-forming units/mL, as determined by absorbance at $600 \mathrm{~nm}$, and ND$\mathrm{AMB}^{72 \mathrm{C}}$ or AmBisome were added to a final concentration of $0.125-2 \mathrm{mg} / \mathrm{L}$. All steps were performed at $35^{\circ} \mathrm{C}$. To quantify yeast viability, aliquots were withdrawn from the culture, washed twice to eliminate residual $\mathrm{AMB}$, then sixfold serial dilutions were cultured on yeast extract-malt extract agar at $30^{\circ} \mathrm{C}$. Plates were counted after 48 hours of incubation.

\section{ND-AMB toxicity testing}

A single injection (between 2 and $15 \mathrm{mg} / \mathrm{kg}$ ) of ND-AMB ${ }^{35 \mathrm{C}}$, $\mathrm{ND}-\mathrm{AMB}^{55 \mathrm{C}}, \mathrm{ND}-\mathrm{AMB}^{72 \mathrm{C}}$, or DOC-AMB was administered 
via the lateral tail vein to healthy female CD-1 mice. Fortyeight hours later, blood was collected by cardiac puncture into lithium heparin Microtainers ${ }^{\circledR}$ (BD, Franklin Lakes, $\mathrm{NJ}, \mathrm{USA}$ ) and spun at $8,000 \mathrm{~g}, 4^{\circ} \mathrm{C}$ for 10 minutes to isolate plasma. Samples were frozen at $-80^{\circ} \mathrm{C}$ until use. Serum chemistry analysis was performed by the UC Davis Comparative Pathology Lab (Davis, CA, USA).

\section{Effect of ND-AMB treatment}

\section{on candidiasis infection}

\section{in immune-competent model}

$\mathrm{Balb} / \mathrm{c}$ female mice were inoculated intravenously (IV) with $2.0 \times 10^{4}$ C. albicans SC5314 on day 0. Treatment consisted of ND-AMB ${ }^{72 C}(0.25,0.5,1,3 \mathrm{mg} / \mathrm{kg}), \operatorname{AmBisome}(1,3,6 \mathrm{mg} / \mathrm{kg})$, DOC-AMB $(0.5,1 \mathrm{mg} / \mathrm{kg})$ or isotonic dextrose administered IV on days 2, 3, 4, and 5. Survivors were killed on day 6.

\section{Effect of ND-AMB treatment on candidiasis infection in immunosuppressed model}

CD-1 females were rendered leukopenic by cyclophosphamide monohydrate (Sigma-Aldrich, St Louis, MO, USA), administered intraperitoneally at $200 \mathrm{mg} / \mathrm{kg} 3$ days prior to inoculation, with maintenance dose of $75 \mathrm{mg} / \mathrm{kg} 1$ day after inoculation and every 3 days thereafter. Inoculum consisted of $1.3 \times 10^{3}$ colony-forming units/g C. albicans SC5314 administered IV on day 0 . Animals in the treatment group(s) received a single IV injection of $\mathrm{ND}-\mathrm{AMB}^{72 \mathrm{C}}$ or $\mathrm{L}-\mathrm{AMB}$ (both at $0.03,0.1,0.3,1,3 \mathrm{mg} / \mathrm{kg}$ ) on day 1 . Health was monitored daily, and survivors were killed on day 22 .

\section{Results \\ Generation of NanoDisk containing super aggregated $A M B$}

Application of heat to AMB in an aqueous environment induces the formation of a super aggregated state and concomitant reductions of monomers and oligomers. This conversion is readily observed by light-absorbance spectroscopy, as each state exhibits a unique absorption spectrum. The relative concentration of each species in solution may be approximated by the intensity and $\lambda_{\max }$. For AMB in water, the $\lambda_{\max }$ of absorbance for monomer $(408-416 \mathrm{~nm})$, oligomer $(\sim 339 \mathrm{~nm})$ and super aggregate (322 nm) have been previously described. ${ }^{12}$ Similarly, we found that AMB dissolved in DMSO exhibited a $\lambda_{\max }$ of absorbance at $416 \mathrm{~nm}$ (Figure 1A), consistent with the
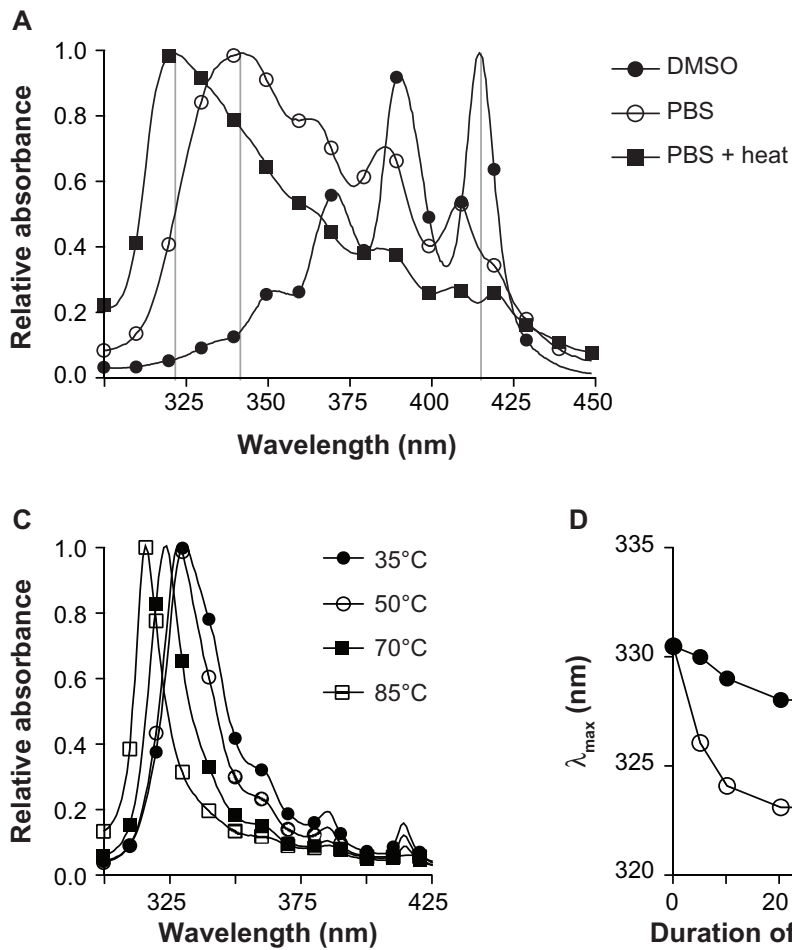

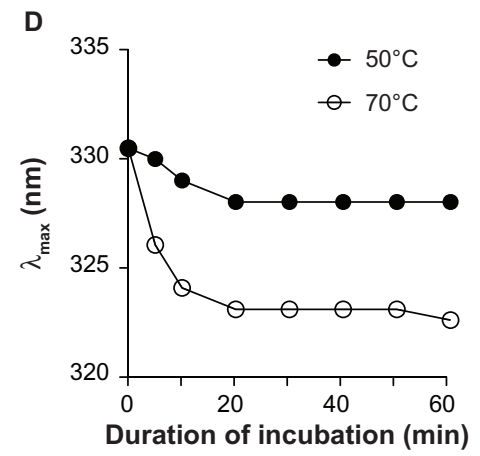

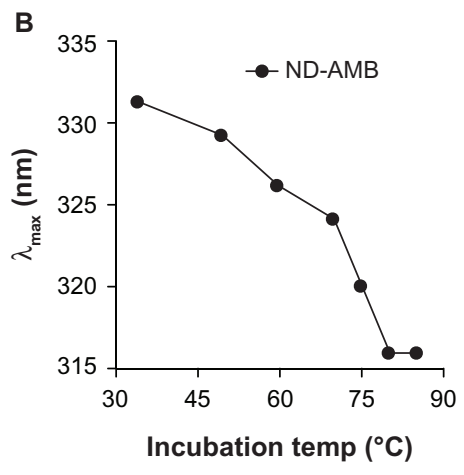

E

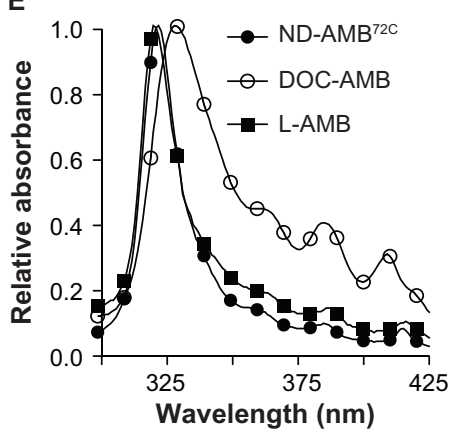

Figure I (A-E) Heating induces a shift in the absorbance spectrum of NanoDisk-amphotericin B (ND-AMB) consistent with the formation of super aggregated AMB. (A) AMB was dissolved to $10 \mathrm{mg} / \mathrm{L}$ in dimethyl sulfoxide (DMSO) or phosphate-buffered saline (PBS), followed by a 30 -minute incubation at $70^{\circ} \mathrm{C}$ and subsequent absorptionspectra measurement. (B) Summary of the wavelength of maximal absorbance $\left(\lambda_{\text {max }}\right)$ values for ND-AMB after incubation between $35^{\circ} \mathrm{C}$ and $85^{\circ} \mathrm{C}$ for 30 minutes. (C) Absorption spectra of ND-AMB heated at increasing temperatures for 30 minutes. (D) Time dependence of the spectroscopic shift in $\lambda_{\max }$ was monitored over a 60-minute incubation at the temperatures indicated. (E) Absorbance spectra of ND-AMB and commercially available formulations of AMB measured in aqueous buffer. Abbreviations: DOC, deoxycholate; L-AMB, liposomal amphotericin B. 
monomeric form. Further, AMB's $\lambda_{\text {max }}$ of absorbance in PBS was $342 \mathrm{~nm}$, but transitioned to $323 \mathrm{~nm}$ following incubation at $70^{\circ} \mathrm{C}$, indicating that the drug had converted to the super aggregated form.

To gain insights into the effects of heating, ND-AMB was heated and the absorbance spectra before and after heating were monitored to detect changes in the aggregation state of AMB (Figure 1B and C). Incubating the ND-AMB complex at temperatures between $50^{\circ} \mathrm{C}$ and $85^{\circ} \mathrm{C}$ induced a temperature-dependent blue shift in $\lambda_{\max }$. A maximal shift to $316 \mathrm{~nm}$ was observed after incubation at $80^{\circ} \mathrm{C}$, with no additional shift observed upon further incubation at $85^{\circ} \mathrm{C}$. An incubation of 20 minutes was sufficient to achieve maximal shift in $\lambda_{\text {max }}$ for a given temperature (Figure 1D). When ND-AMB was incubated at temperatures $\geq 75^{\circ} \mathrm{C}$, samples became turbid coincident with a loss of $>10 \%$ AMB upon sterile filtration $(0.2 \mu \mathrm{m})$, suggesting a reduction of solubility. $\mathrm{ND}-\mathrm{AMB}$ incubated at $72^{\circ} \mathrm{C}$ for 30 minutes (ND-AMB ${ }^{72 \mathrm{C}}$ ) was fully soluble and exhibited an absorbance spectrum similar to that of L-AMB and aqueous super aggregated AMB (Figure 1E).

\section{Transmission electron microscopic structure of AMB complexes}

Negative-stain transmission electron microscopy was used to examine the structure and size of ND-AMB. Micrographs (Figure 2A and B) illustrate the geometry of the ND-AMB complexes, which are flattened structures, wherein AMB is presumed to be interdigitated within the ND particle phospholipid bilayer, as described by Nguyen et al. ${ }^{16}$ The median diameter of ND-AMB ${ }^{72 C}(80 \pm 25 \mathrm{~nm}$, Figure $2 \mathrm{~A})$ was larger than ND-AMB incubated at $35^{\circ} \mathrm{C}\left(\mathrm{ND}-\mathrm{AMB}^{35 \mathrm{C}}\right)$

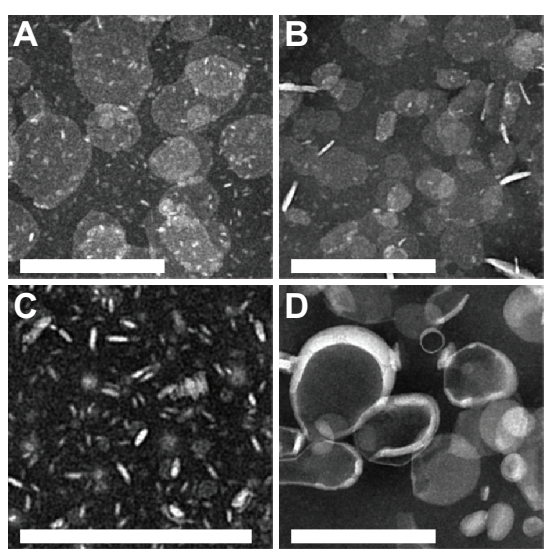

Figure 2 (A-D) Negative-stain transmission electron micrographs of NanoDiskamphotericin B (ND-AMB) and liposomal AMB (L-AMB). (A) ND-AMB ${ }^{72 C}$, (B) ND-AMB ${ }^{35 C}$, (C) ND vehicle, and (D) L-AMB imaged by electron microscopy using magnification of $12,000 \times$ or $20,000 \times$. Bar $=200 \mathrm{~nm}$.

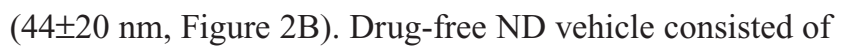
small discoidal structures $(10 \pm 3.6 \mathrm{~nm})$ capable of forming rouleaux. These drug-free particles appeared as en face disks or electron lucent rod-like structures consistent with disks standing on edge (Figure $2 \mathrm{C}$ ). Because of the relative ratio of edge surface to top/bottom surface, the larger-diameter $\mathrm{ND}-\mathrm{AMB}^{35 \mathrm{C}}$ and ND-AMB ${ }^{72 \mathrm{C}}$ particles (relative to drug-free ND particles) predominantly present as en face disks. The structure and size of L-AMB (Figure 2D) was consistent with a liposome $(63 \pm 42 \mathrm{~nm})$, similar to published values. ${ }^{22}$

\section{In vivo toxicity of heat-treated ND-AMB}

The relationship between ND-AMB incubation temperature and acute toxicity was evaluated in mice. Mice were injected with $\mathrm{ND}-\mathrm{AMB}$ incubated at $35^{\circ} \mathrm{C}, 55^{\circ} \mathrm{C}$, or $72^{\circ} \mathrm{C}$ for 30 minutes $\left(\mathrm{ND}-\mathrm{AMB}^{35 \mathrm{C}}, \mathrm{ND}-\mathrm{AMB}^{55 \mathrm{C}}, \mathrm{ND}-\mathrm{AMB}^{72 \mathrm{C}}\right.$ ) or DOC-AMB, and toxicity was assessed by serum chemistry analysis (Table 1). Blood urea nitrogen and creatinine were considered elevated in an individual mouse if both markers were above baseline by more than twice the standard deviation. The maximum doses for which none of the animals had elevated kidney markers were 2,4 , and $12 \mathrm{mg} / \mathrm{kg}$ for ND-AMB incubated at $35^{\circ} \mathrm{C}, 55^{\circ} \mathrm{C}$, and $72^{\circ} \mathrm{C}$, respectively. Despite the observation that kidney markers were elevated in three of five mice that received ND-AMB ${ }^{72 C}$ at $15 \mathrm{mg} / \mathrm{kg}$, these levels were not statistically distinguishable from baseline by one-way analysis of variance. The lowest dose of DOC-AMB to produce lethality by 48 hours postinjection was $2 \mathrm{mg} / \mathrm{kg}$ (one of three mice), while the lowest lethal dose of ND-AMB ${ }^{35 \mathrm{C}}$ was $4 \mathrm{mg} / \mathrm{kg}$ (one of five mice) and $8 \mathrm{mg} / \mathrm{kg}$ (one of five mice) for ND-AMB ${ }^{55 \mathrm{C}}$. In contrast, the highest dose of ND-AMB ${ }^{72 \mathrm{C}}$ administered $(15 \mathrm{mg} / \mathrm{kg}$ ) was not lethal, validating the relationship between AMB super aggregation and increased ND-AMB maximum safe dose.

\section{In vitro potency of ND-AMB}

The antifungal efficacy of ND-AMB against $C$. albicans and $A$. fumigatus was tested by in vitro growth-inhibition assay. The MIC values of $\mathrm{ND}-\mathrm{AMB}^{72 \mathrm{C}}$ and $\mathrm{ND}-\mathrm{AMB}^{35 \mathrm{C}}$ were identical, inhibiting all visible growth of $C$. albicans or A. fumigatus at $0.125 \mathrm{mg} / \mathrm{L}$ and $0.5 \mathrm{mg} / \mathrm{L} \mathrm{AMB}$, respectively (Table 2). ND-AMB was fourfold more potent than L-AMB when tested against $C$. albicans, and sixfold more potent versus A. fumigatus. The MIC of ND-AMB for C. albicans was equal to DOC-AMB $(0.125 \mathrm{mg} / \mathrm{L})$ but twofold more potent against $A$. fumigatus than DOC-AMB (0.5 versus $1 \mathrm{mg} / \mathrm{L})$. MICs obtained for DOC-AMB and L-AMB were consistent with published values. ${ }^{23,24}$ 
Table I Effects of ND-AMB on serum chemistries in mice

\begin{tabular}{|c|c|c|c|c|c|c|c|}
\hline Treatment & $\begin{array}{l}\text { Dose AMB } \\
(\mathrm{mg} / \mathrm{kg})\end{array}$ & Survival & $\begin{array}{l}\text { Elevated kidney } \\
\text { markers }\end{array}$ & $\begin{array}{l}\text { Creat }(\mathrm{mg} / \mathrm{dL}) \\
\text { mean }(\mathrm{SD})\end{array}$ & $\begin{array}{l}\text { BUN (mg/dL) } \\
\text { mean (SD) }\end{array}$ & $\begin{array}{l}\text { ALT (U/L) } \\
\text { mean (SD) }\end{array}$ & $\begin{array}{l}\text { AST }(U / L) \\
\text { mean }(S D)\end{array}$ \\
\hline Baseline (D5W) & - & $5 / 5$ & NA & $0.12(0.01)$ & $20.5(2.1)$ & $34.1(2.7)$ & $104(44)$ \\
\hline ND-AMB $35 \mathrm{C}$ & 2 & $5 / 5$ & $0 / 5$ & $0.1(0.01)$ & $21.6(1.2)$ & $32(\mathrm{II})$ & $88.8(40)$ \\
\hline ND-AMB ${ }^{35 C}$ & 3 & $5 / 5$ & $3 / 5$ & $0.17(0.09)$ & $60.3(32.8)$ & 7I (83) & 142 (138) \\
\hline ND-AMB ${ }^{35 C}$ & 4 & $4 / 5$ & $3 / 4$ & $0.4 \mathrm{I}(0.32)$ & $128(75.1)$ & $45(12)$ & I 85 (57) \\
\hline ND-AMB ${ }^{55 C}$ & 4 & $5 / 5$ & $0 / 5$ & $0.07(0.02)$ & $22(2.6)$ & $73(37)$ & $284(133)$ \\
\hline ND-AMB ${ }^{55 C}$ & 8 & $4 / 5$ & $4 / 5$ & $1.7(0.83)^{* *}$ & $330(120)^{* *}$ & $129(3 \mathrm{I})^{*}$ & $382(6 \mathrm{I})^{*}$ \\
\hline ND-AMB ${ }^{72 C}$ & 10 & $5 / 5$ & $0 / 5$ & $0.13(0.04)$ & $22.8(5.1)$ & $69(19)$ & $160(130)$ \\
\hline ND-AMB ${ }^{72 C}$ & 12 & $5 / 5$ & $0 / 5$ & $0.08(0.04)$ & $23(10.3)$ & $135(64)$ & $219(115)$ \\
\hline ND-AMB ${ }^{72 C}$ & 15 & $5 / 5$ & $3 / 5$ & $0.39(0.49)$ & 99.5 (127) & 56.5 & $132(|2|)$ \\
\hline DOC-AMB & 2 & $2 / 3$ & $0 / 2$ & $0.07(0.01)$ & $16.5(5.1)$ & $83(52)$ & $176(102)$ \\
\hline DOC-AMB & 3 & $2 / 3$ & $0 / 2$ & $0.51(-)$ & $160.2(-)$ & $66(-)$ & $237(-)$ \\
\hline
\end{tabular}

Notes: $* P<0.05, * * P<0.0001$ compared to baseline by one-way analysis of variance.

Abbreviations: ND, NanoDisk; AMB, amphotericin B; NA, not applicable; Creat, creatinine; BUN, blood urea nitrogen; ALT, alanine aminotransferase; AST, aspartate aminotransferase; SD, standard deviation; DOC, deoxycholate.

ND-AMB ${ }^{72 C}$ and L-AMB candidacidal kinetics were determined using an in vitro fungicidal assay. C. albicans was incubated with ND-AMB ${ }^{72 \mathrm{C}}(0.125-2 \mathrm{mg} / \mathrm{L}$, one- to 16 -fold over MIC) or L-AMB $(0.5-2 \mathrm{mg} / \mathrm{L}$, one- to fourfold over MIC) at established inhibitory concentrations (Table 2), and yeast viability was monitored throughout a 6-hour exposure period (Figure 3). ND-AMB ${ }^{72 \mathrm{C}}$ at the MIC concentration of $0.125 \mathrm{mg} / \mathrm{L}$ reduced viable yeast counts by two orders of magnitude in 6 hours, while yeast viability increased nearly tenfold in the presence of L-AMB at an MIC concentration of $0.5 \mathrm{mg} / \mathrm{L}$. L-AMB at $2 \mathrm{mg} / \mathrm{L}$, fourfold the MIC concentration, was required to achieve fungicidal activity comparable to one-sixteenth the concentration of ND-AMB ${ }^{72 C}$. These data indicate that the candidacidal concentration of ND-AMB ${ }^{72 C}$ is approximately 16 -fold lower than that of L-AMB.

\section{Efficacy in murine models of candidiasis}

An acute murine model of disseminated candidiasis infection in immune-competent hosts was used to compare the efficacy of $\mathrm{ND}-\mathrm{AMB}^{72 \mathrm{C}}$ to existing $\mathrm{AMB}$ therapies. L-AMB and DOC-AMB were dose-matched to standard clinical levels (Figure 4). ND-AMB ${ }^{72 C}$ therapy between 0.25 and $3 \mathrm{mg} / \mathrm{kg}$ improved survival relative to untreated controls $(P<0.05)$,

Table 2 In vitro antifungal potency of ND-AMB

\begin{tabular}{lll}
\hline Formulation & C. albicans MIC (mg/L) & A. fumigatus MIC (mg/L) \\
\hline ND-AMB $^{35 C}$ & 0.125 & 0.5 \\
ND-AMB $^{72 C}$ & 0.125 & 0.5 \\
L-AMB & 0.5 & 3 \\
DOC-AMB & 0.125 & $\mathrm{I}$ \\
\hline
\end{tabular}

Note: Reported values represent an average of two separate experiments, each performed in duplicate.

Abbreviations: C. albicans, Candida albicans; A. fumigatus, Aspergillus fumigatus; MIC, minimal inhibitory concentration; ND, NanoDisk; AMB, amphotericin B; L, liposomal; DOC, deoxycholate. with $100 \%$ survival in mice that received $3 \mathrm{mg} / \mathrm{kg} \mathrm{ND}-\mathrm{AMB}$ (six of six surviving). On the other hand, mice treated with L-AMB showed lower survival at 3 and $6 \mathrm{mg} / \mathrm{kg}$ (five of six surviving for both groups), while DOC-AMB at $1 \mathrm{mg} / \mathrm{kg}$ also exhibited partial survival (five of six surviving). Mortality was high (one of six surviving) among untreated infected controls. No statistically significant differences between antifungal treatments were observed. These data indicate that $\mathrm{ND}-\mathrm{AMB}^{72 \mathrm{C}}$ performs at least as well as DOC-AMB (the most potent fungicidal form of AMB) and L-AMB (one of the safest forms of AMB) in an acute candidiasis infection model.

The relative potency of $\mathrm{ND}-\mathrm{AMB}^{72 \mathrm{C}}$ was also compared to L-AMB using an immune-suppressed candidiasis model. Leukopenic mice were infected with $C$. albicans, and the response to $\mathrm{ND}-\mathrm{AMB}^{72 \mathrm{C}}$ or $\mathrm{L}-\mathrm{AMB}$ was evaluated at one of several doses that spanned the therapeutic threshold. ND$\mathrm{AMB}^{72 \mathrm{C}}$ at $0.3 \mathrm{mg} / \mathrm{kg}$ significantly improved survival relative to controls $(P<0.001)$, with $86 \%$ of treated mice surviving versus $0 \%$ in the untreated controls. In contrast, all mice that received L-AMB at $0.3 \mathrm{mg} / \mathrm{kg}$ succumbed to infection by day 19 , with a median survival of 13 days versus a median survival of 18 days for ND-AMB ${ }^{72 C}$ (Figure 5A). To establish relative potency, the effective dose required to achieve $50 \%$ survival $\left(\mathrm{ED}_{50}\right)$ was calculated by plotting response to therapy versus log-transformed dose (Figure 5B). This analysis indicated that $\mathrm{ND}-\mathrm{AMB}^{72 \mathrm{C}}$ treatment was threefold more potent than $\mathrm{L}-\mathrm{AMB}\left(\mathrm{ED}_{50}=0.29\right.$ versus $\left.0.89, P>0.05\right)$.

\section{Discussion}

The present study describes a novel formulation of ND$\mathrm{AMB}^{72 \mathrm{C}}$, an experimental antifungal therapy with a high therapeutic index. Presently, the available options for AMB 


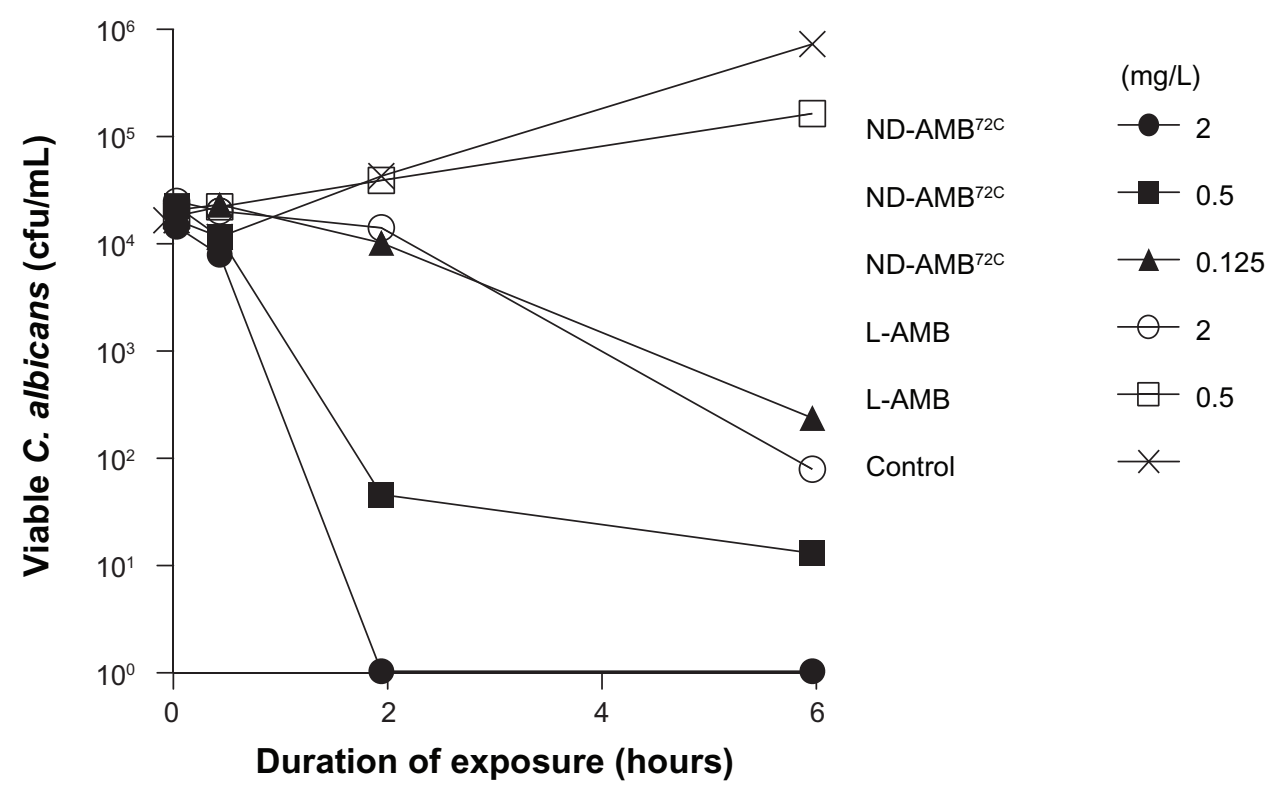

Figure 3 NanoDisk-amphotericin B (ND-AMB) ${ }^{72 C}$ kills Candida albicans more rapidly than liposomal AMB (L-AMB). To establish the fungicidal kinetics of ND-AMB ${ }^{72 C}$ and L-AMB, agents were added to log-phase $C$. albicans culture for up to 6 hours. At time points indicated, aliquots of culture were withdrawn and cultured to quantify viable yeast. Results are representative of three individual experiments.

therapy consist of DOC-AMB, which is highly toxic, or lipid-AMB formulations, which exhibit improved safety yet attenuated antifungal potency in comparison to DOC-AMB. Here, we show that an AMB formulation composed of super aggregated AMB contained within the ND drug-delivery bioparticle has fungicidal potency equivalent to the most potent $\mathrm{AMB}$ formulation, DOC-AMB, but is as safe as the safest AMB formulation - L-AMB.

To investigate the clinical relevance of ND-AMB as a therapy for invasive fungal infections, several comparator formulations were selected for these studies. DOC-AMB was chosen for its unmatched fungicidal potency, and L-AMB was chosen as a benchmark for safety. While a growing number of similar lipid-based formulations of AMB are being explored for clinical utility, these products are either not widely available or do not surpass DOC-AMB and L-AMB in potency or safety, respectively. ${ }^{25-28}$ Similarly, whereas a super aggregate form of DOC-AMB generated by heating was first described nearly 25 years ago, the improvement to therapeutic index was marginal, with an $\mathrm{LD}_{50}$ in mice 1.5 -fold higher ( 9 versus $6 \mathrm{mg} / \mathrm{kg}$ ) than the commercially available unheated form. ${ }^{10,29}$ These disappointing in vivo findings were likely due to poor stability of the aqueous super aggregate form in the biological milieu. ${ }^{5,30}$ Lipid-bound AMB reduces the release of toxic AMB species, and thus the ND-AMB vehicle stabilizes the super aggregate. ${ }^{5}$ The present study assessed the therapeutic potential of a unique super aggregate ND-AMB.
Under our experimental conditions, ND-AMB incubated at $72^{\circ} \mathrm{C}$ had spectroscopic properties consistent with the conversion of oligomeric AMB to super aggregate. ${ }^{12}$ At higher temperatures $\left(\geq 75^{\circ} \mathrm{C}\right)$, ND-AMB became insoluble, suggesting that either the ND became irreversibly denatured at this temperature or super aggregates grew too large to remain stably incorporated in the ND. Interestingly, the spectra of L-AMB and ND-AMB ${ }^{72 C}$ were similar, suggesting that both formulations contain a similar proportion of super aggregated AMB. Inclusion of super aggregated AMB in L-AMB is consistent with both the reported safety profile and high temperatures typically employed to formulate stearic acidcontaining liposomes such as L-AMB. ${ }^{31}$

The biological basis for super aggregate AMB's improved therapeutic index remains controversial, along with the mechanism of action and toxicity of the drug in general. One compelling line of evidence, however, relates to the high affinity of AMB for ergosterol, the predominant sterol in fungal membranes. In that study, super aggregate AMB and DOC-AMB were observed to be equally efficient at promoting ionic permeability, a hallmark of AMB's toxicity, of synthetic ergosterol-containing vesicles. However, super aggregated AMB, but not DOC-AMB, remained strikingly inactive when exposed to vesicles containing cholesterol., ${ }^{5,30}$ These findings suggest that a fungal membrane facilitates the dissociation of super aggregated AMB back into a toxic form and provides a mechanistic basis for improved therapeutic index associated with super aggregates and heat treatment. 

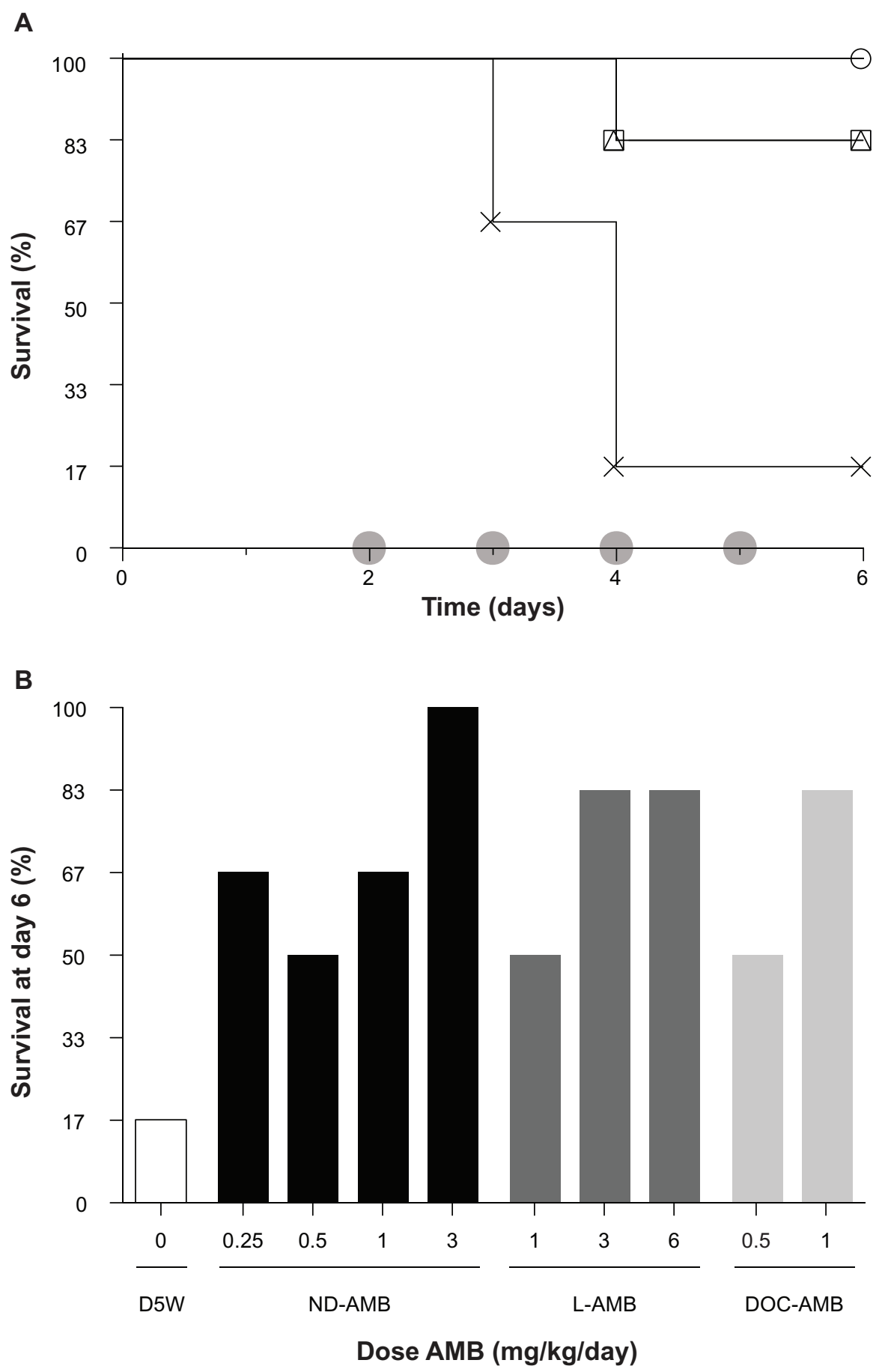

Figure 4 (A and B) NanoDisk-amphotericin B (ND-AMB) ${ }^{72 C}$ is an effective treatment for disseminated Candida albicans infection in immune-competent mice. (A) KaplanMeier plots of select groups $(n=6)$ infected on day 0 and treated on days indicated (shaded circles). Treated mice received either ND-AMB ${ }^{72 C}$ at 3 mg/kg/day (open circles), liposomal AMB (L-AMB) at $3 \mathrm{mg} / \mathrm{kg} /$ day (open squares), deoxycholate (DOC) at I mg/kg/day (open triangles), or isotonic dextrose as control (crosses). (B) Survival for all groups is summarized on day 6 for treatment groups ND-AMB ${ }^{72 C}$ (closed bars), L-AMB (dark shading), DOC-AMB (light shading), or isotonic dextrose (open bars).

Our data demonstrate that the conversion of AMB within ND-AMB to its super aggregated form dramatically reduces toxicity in vivo. The maximum dose at which no evidence of nephrotoxicity was observed for heat-treated $\mathrm{ND}-\mathrm{AMB}^{72 \mathrm{C}}$ was increased sixfold, relative to unheated ND-AMB. Since the plasma pharmacokinetics of ND-AMB are negligibly affected by heating (unpublished observation), the improved tolerability is not simply a consequence of altered clearance.

We have also demonstrated that ND-AMB ${ }^{72 C}$ is a highly efficacious treatment for invasive candidiasis in mice. ND$\mathrm{AMB}^{72 \mathrm{C}}$ was the only therapy to produce complete survival 


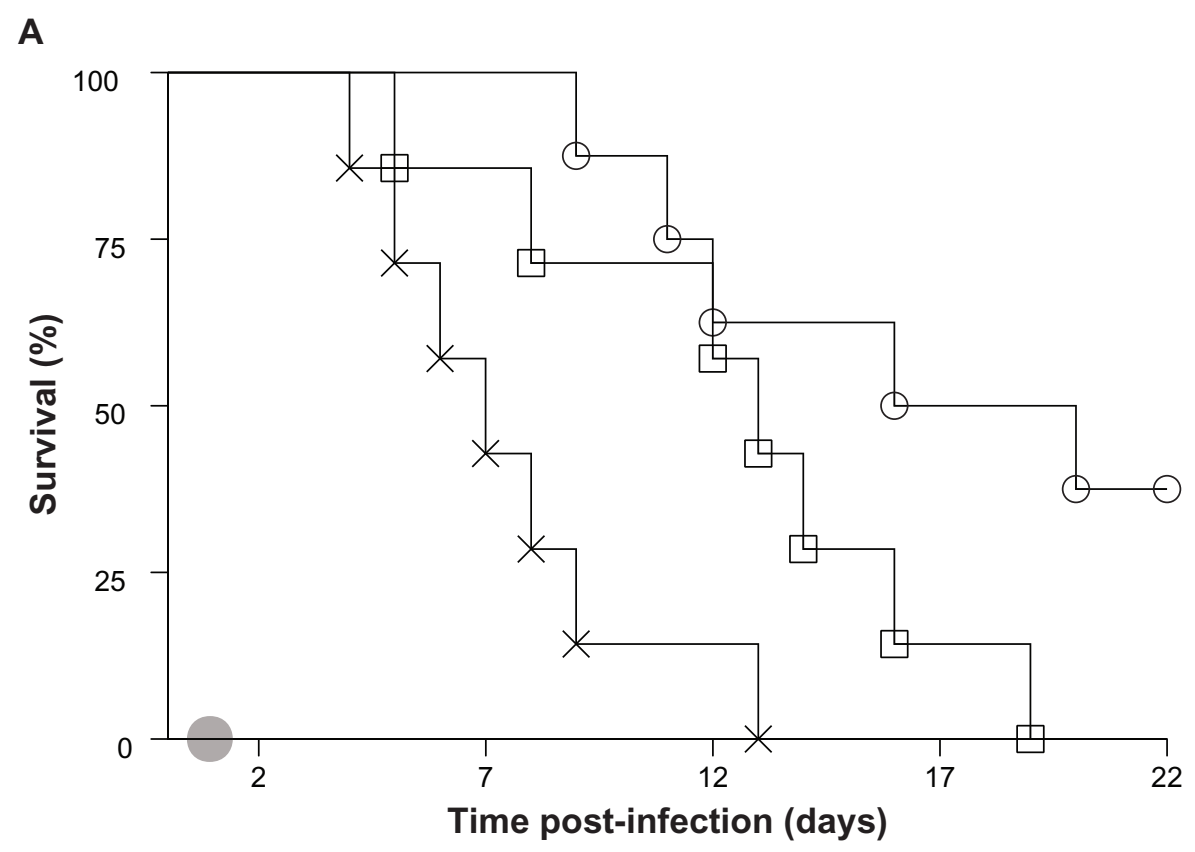

B

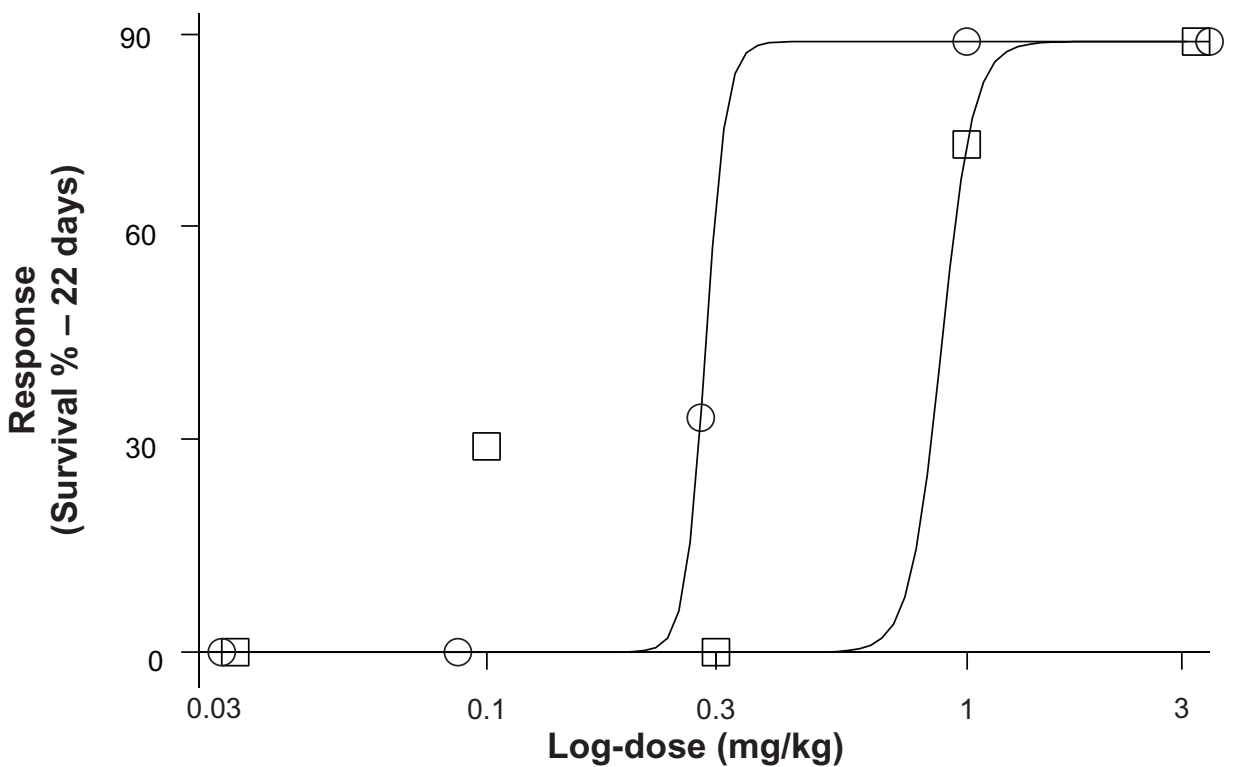

Figure 5 (A and B) NanoDisk-amphotericin B (ND-AMB) ${ }^{72 C}$ is a highly potent therapy for the treatment of Candida albicans infection in immune-suppressed mice. Persistently leukopenic mice $(n=7)$ were inoculated on day 0 . Treatment consisted of ND-AMB ${ }^{72 C}$ (open circles), liposomal AMB (L-AMB) dosed at 0.03 , 0.1, 0.3, I, or $3 \mathrm{mg} / \mathrm{kg}$, or isotonic dextrose (crosses), administered as a single intravenous bolus on day I (shaded circle). (A) Kaplan-Meier plots for groups that received $0.3 \mathrm{mg} / \mathrm{kg}$ AMB. (B) Dose-response plot for all treatment groups plotted against log-transformed dose. Solid lines represent dose response for each treatment generated using a nonlinear regression model fit to survival data on day 22.

in the immune-competent infection model at a dose of $3 \mathrm{mg} / \mathrm{kg}$, compared to $83 \%$ survival for L-AMB and DOCAMB. Further, the $\mathrm{ED}_{50}$ of $\mathrm{ND}-\mathrm{AMB}^{72 \mathrm{C}}$ was threefold lower than that of L-AMB in a leukopenic infection model, and achieved a maximal response with a single injection at $1 \mathrm{mg} / \mathrm{kg}$. ND-AMB ${ }^{72 \mathrm{C}}$ therapy also produces no evidence of nephrotoxicity at doses up to $12 \mathrm{mg} / \mathrm{kg}$ in mice, while providing in vivo efficacy as good as or better than DOC-AMB or
L-AMB. Importantly, the heat-induced formation of super aggregated $\mathrm{AMB}$ in $\mathrm{ND}-\mathrm{AMB}^{72 \mathrm{C}}$ dramatically improves the safety of the drug without compromising effectiveness. These findings suggest that the in vivo efficacy of $\mathrm{ND}-\mathrm{AMB}^{72 \mathrm{C}}$ may surpass existing formulations of AMB. Taken together, these data indicate that ND-AMB ${ }^{72 C}$, which contains super aggregated $\mathrm{AMB}$, is a promising novel therapy for invasive fungal disease. 


\section{Acknowledgments}

We are indebted to Bradley Hammerson, Cori Limbaugh, and Andrea Agcaoili for their assistance with animal studies and in vitro analysis of AMB formulation efficacy, as well as Jinny Wong and the Gladstone Institutes for electron micrographic studies. Lastly, we would like to thank Michelle Call and Robert Ryan for their many suggestions and intellectual contributions. This work was supported by the National Institutes of Health Small Business Initiative Research program (5R44AI066444-05). The content is solely the responsibility of the authors, and does not necessarily represent the official views of the National Institutes of Health.

\section{Disclosure}

BLB, BL, and SFC are employees of Lypro Biosciences Inc. MNO and TMF hold shares in or receive consulting fees from Lypro Biosciences Inc. Lypro Biosciences holds intellectual property pertaining to the use of the NanoDisk drug-delivery platform. The other authors report no conflicts of interest in this work.

\section{References}

1. Walker LA, Gow NA, Munro CA. Fungal echinocandin resistance. Fungal Genet Biol. 2010;47(2):117-126.

2. Verweij PE, Snelders E, Kema GH, Mellado E, Melchers WJ. Azole resistance in Aspergillus fumigatus: a side-effect of environmental fungicide use? Lancet Infect Dis. 2009;9(12):789-795.

3. Snelders E, van der Lee HA, Kuijpers J, et al. Emergence of azole resistance in Aspergillus fumigatus and spread of a single resistance mechanism. PLoS Med. 2008;5(11):e219.

4. Beyda ND, Lewis RE, Garey KW. Echinocandin resistance in Candida species: mechanisms of reduced susceptibility and therapeutic approaches. Ann Pharmacother. 2012;46(7-8):1086-1096.

5. Brajtburg J, Bolard J. Carrier effects on biological activity of amphotericin B. Clin Microbiol Rev. 1996;9(4):512-531.

6. Walsh TJ, Finberg RW, Arndt C, et al. Liposomal amphotericin B for empirical therapy in patients with persistent fever and neutropenia. National Institute of Allergy and Infectious Diseases Mycoses Study Group. N Engl J Med. 1999;340(10):764-771.

7. Andes D, Safdar N, Marchillo K, Conklin R. Pharmacokineticpharmacodynamic comparison of amphotericin B (AMB) and two lipid-associated AMB preparations, liposomal AMB and AMB lipid complex, in murine candidiasis models. Antimicrob Agents Chemother. 2006;50(2):674-684.

8. Espada R, Valdespina S, Alfonso C, Rivas G, Ballesteros MP, Torrado JJ. Effect of aggregation state on the toxicity of different amphotericin B preparations. Int J Pharm. 2008;361(1-2):64-69.

9. van Etten EW, van Vianen W, Roovers P, Frederik P. Mild heating of amphotericin B-desoxycholate: effects on ultrastructure, in vitro activity and toxicity, and therapeutic efficacy in severe candidiasis in leukopenic mice. Antimicrob Agents Chemother. 2000;44(6):1598-1603.

10. Petit C, Chéron M, Joly V, Rodrigues JM, Bolard J, Gaboriau F. Invivo therapeutic efficacy in experimental murine mycoses of a new formulation of deoxycholate-amphotericin B obtained by mild heating. J Antimicrob Chemother. 1998;42(6):779-785.

11. Gaboriau F, Chéron M, Petit C, Bolard J. Heat-induced superaggregation of amphotericin B reduces its in vitro toxicity: a new way to improve its therapeutic index. Antimicrob Agents Chemother. 1997;41(11): 2345-2351.
12. Gaboriau F, Chéron M, Leroy L, Bolard J. Physico-chemical properties of the heat-induced 'superaggregates' of amphotericin B. Biophys Chem. 1997;66(1):1-12.

13. Janoff AS, Boni LT, Popescu MC, et al. Unusual lipid structures selectively reduce the toxicity of amphotericin B. Proc Natl Acad Sci USA. 1988;85(16):6122-6126.

14. Ghosh M, Singh AT, Xu W, Sulchek T, Gordon LI, Ryan RO. Curcumin nanodisks: formulation and characterization. Nanomedicine. 2011;7(2): $162-167$.

15. Iovannisci DM, Beckstead JA, Ryan RO. Targeting nanodisks via a single chain variable antibody-apolipoprotein chimera. Biochem Biophys Res Commun. 2009;379(2):466-469.

16. Nguyen TS, Weers PM, Raussens V, et al. Amphotericin B induces interdigitation of apolipoprotein stabilized nanodisk bilayers. Biochim Biophys Acta. 2008;1778(1):303-312.

17. Oda MN, Hargreaves PL, Beckstead JA, Redmond KA, van Antwerpen R, Ryan RO. Reconstituted high density lipoprotein enriched with the polyene antibiotic amphotericin B. J Lipid Res. 2006;47(2):260-267.

18. Singh AT, Evens AM, Anderson RJ, et al. All trans retinoic acid nanodisks enhance retinoic acid receptor mediated apoptosis and cell cycle arrest in mantle cell lymphoma. B J Haematol. 2010;150(2):158-169.

19. Ryan RO, Forte TM, Oda MN. Optimized bacterial expression of human apolipoprotein A-I. Protein Expr Purif. 2003;27(1):98-103.

20. Rex JH, Alexander BD, Andes D, et al. Reference Method for Broth Dilution Antifugal Susceptibility Testing of Yeasts; Approved StandardThird Edition. Wayne (PA): Clinical and Laboratory Standards Institute; 2008.

21. Rex JH, Alexander BD, Andes D, et al. Reference Method for Broth Dilution Antifungal Susceptibility Testing of Filamentous Fungi; Approved Standard - Second Edition. Wayne (PA): Clinical and Laboratory Standards Institute; 2008.

22. Proffitt RT, Satorius A, Chiang SM, Sullivan L, Adler-Moore JP. Pharmacology and toxicology of a liposomal formulation of amphotericin B (AmBisome) in rodents. J Antimicrob Chemother. 1991; 28 Suppl B:49-61.

23. Takemoto K, Yamamoto Y, Ueda Y, Sumita Y, Yoshida K, Niki Y. Comparative studies on the efficacy of AmBisome and Fungizone in a mouse model of disseminated aspergillosis. J Antimicrob Chemother. 2004;53(2):311-317.

24. Anaissie E, Paetznick V, Proffitt R, Adler-Moore J, Bodey GP. Comparison of the in vitro antifungal activity of free and liposome-encapsulated amphotericin B. Eur J Clin Microbiol Infect Dis. 1991;10(8):665-668.

25. Wingard JR, White MH, Anaissie E, Raffalli J, Goodman J, Arrieta A. A randomized, double-blind comparative trial evaluating the safety of liposomal amphotericin B versus amphotericin B lipid complex in the empirical treatment of febrile neutropenia. L Amph/ABLC Collaborative Study Group. Clin Infect Dis. 2000;31(5):1155-1163.

26. Bowden R, Chandrasekar P, White MH, et al. A double-blind, randomized, controlled trial of amphotericin $\mathrm{B}$ colloidal dispersion versus amphotericin B for treatment of invasive aspergillosis in immunocompromised patients. Clin Infect Dis. 2002;35(4):359-366.

27. Sanath SS, Gogtay NJ, Kshirsagar NA. Post-marketing study to assess the safety, tolerability and effectiveness of Fungisome: an Indian liposomal amphotericin B preparation. J Postgrad Med. 2005;51 Suppl 1: S58-S63.

28. Olson JA, Adler-Moore JP, Jensen GM, Schwartz J, Dignani MC, Proffitt RT. Comparison of the physicochemical, antifungal, and toxic properties of two liposomal amphotericin B products. Antimicrob Agents Chemother. 2008;52(1):259-268.

29. Bau P, Bolard J, Dupouy-Camet J. Heated amphotericin to treat leishmaniasis. Lancet Infect Dis. 2003;3(4):188.

30. Baas B, Kindt K, Scott A, Scott J, Mikulecky P, Hartsel SC. Activity and kinetics of dissociation and transfer of amphotericin B from a novel delivery form. AAPS PharmSci. 1999;1(3):E10.

31. van Etten EW, ten Kate MT, Stearne LE, Bakker-Woudenberg IA. Amphotericin B liposomes with prolonged circulation in blood: in vitro antifungal activity, toxicity, and efficacy in systemic candidiasis in leukopenic mice. Antimicrob Agents Chemother. 1995;39(9):1954-1958. 
International Journal of Nanomedicine

Dovepress

\section{Publish your work in this journal}

The International Journal of Nanomedicine is an international, peerreviewed journal focusing on the application of nanotechnology in diagnostics, therapeutics, and drug delivery systems throughou the biomedical field. This journal is indexed on PubMed Central, MedLine, CAS, SciSearch ${ }^{\circledR}$, Current Contents ${ }^{\circledR} /$ Clinical Medicine,
Journal Citation Reports/Science Edition, EMBase, Scopus and the Elsevier Bibliographic databases. The manuscript management system is completely online and includes a very quick and fair peer-review system, which is all easy to use. Visit http://www.dovepress.com/ testimonials.php to read real quotes from published authors.

Submit your manuscript here: http://www.dovepress.com/international-journal-of-nanomedicine-journal 